\title{
LONGITUDINAL EXTENSIVE TRANSVERSE MYELITIS - CASE REPORT
}

Nayara Mota Carvalho ${ }^{1, \star}$, William Barros Hyppolito Ferreira ${ }^{1}$, Vanessa Félix Nascimento Coelho ${ }^{1}$, Maria Verônica Russo Macchi ${ }^{1}$, Carolina Pellisson Carvalho ${ }^{1}$, André Marun Lyrio ${ }^{1}$, Rubens Bonfigliolii ${ }^{1}$, José Alexandre Mendonça ${ }^{1}$, Lucas Eduardo Pedri ${ }^{1}$, Flávia Regina Andrade ${ }^{1}$, Fernanda Bertucci Sanches ${ }^{1}$, Claudia Valéria Vierhout ${ }^{1}$, Marina de Souza Vieira ${ }^{1}$

1.Pontifícia Universidade Católica de Campinas, Campinas (SP), Brazil.

*Corresponding author: naym.carv@gmail.com

\section{BACKGROUND}

Longitudinal extensive transverse myelitis (LETM) is a serious inflammatory medullary syndrome associated with spinal cord lesion spread by three or more vertebral segments seen on magnetic resonance. It is considered a spectrum of neuromyelitis optica (NMO), a disease characterized by serious and recurrent episodes of optical neuritis and myelitis. Neuromyelitis optica is associated with the presence of the specific antibody directed against aquaporin-4 (AQP4-igG), which is present in about $80 \%$ of NMO cases and $40 \%$ of isolated LETM cases. May be primary or secondary to infection or inflammatory activity of autoimmune diseases such as systemic lupus erythematosus.

\section{CASE REPORT}

Patient, 46 years old, female, from Campinas (SP), with previous contact with a patient infected with tuberculosis, presented previous SLE diagnosis with phospholipid antibody syndrome with positive lupus anticoagulant and retinal thrombosis. Symptoms began with amaurosis and with frame of paraplegia followed by urinary retention. Cerebrospinal fluid performed without growth in bacteria, fungi or mycobacterial crops. A neural axis resonance was done that demonstrated optical neuromyelitis and extensive transverse myelitis and the presence of two intradural, tumefactive, contrast-tracking lesions in its periphery and intense restriction to diffusion. She performed exams to determine lupus activity, with reagent anti-DNA, C3 And C4 consumed and negative AQP4-igG dosage. Diagnosis made of les in activity + phospholipid antibody syndrome + NMO with LETM. Laminectomy performed; started treatment for tuberculosis (seen epidemiology); instituted pulse therapy with methylprednisolone $1 \mathrm{~g} /$ day for 3 days and human immunoglobulin $2 \mathrm{~g} / \mathrm{kg}$. Patient evolved with improvement of sensitive level (pubic symphysis for umbilical scar), but maintaining paraplegia.

\section{CONCLUSION}

Longitudinal extensive transverse myelitis is a serious situation which complete recovery is rare. May be secondary to different etiologies such as lupus activity, phospholipid antibody syndrome and infections.

\section{KEYWORDS}

Lupus, Transverse, Myelitis. 